\title{
Impairment of Hemodynamics with Increasing Mean Airway Pressure during High-Frequency Oscillatory Ventilation ${ }^{1}$
}

\author{
JAY H. TRAVERSE, HEIKKI KORVENRANTA, E. MERRILL ADAMS, DAVID A. GOLDTHWAIT, \\ AND WALDEMAR A. CARLO \\ Departments of Pediatrics and Cardiothoracic Surgery, Rainbow Babies and Children's Hospital, Case Western \\ Reserve University, Cleveland, Ohio 44106
}

\begin{abstract}
We investigated the effects of changes in mean airway pressure ( $\overline{\mathbf{P}}$ aw), oscillatory frequency and lung compliance on cardiac output $(\mathrm{CO})$ and pulmonary vascular resistance in seven adult cats $(3.0 \pm 0.6 \mathrm{~kg})$ during highfrequency oscillatory ventilation (HFOV). The cats were anesthetized with chloralose and urethane and ventilated with a high-frequency oscillator at $\overline{\mathrm{P}}$ aw of $4,8,12$, and 16 $\mathrm{cm} \mathrm{H}_{2} \mathrm{O}$ and frequencies of $3,6,12,16$, and $20 \mathrm{~Hz}$. Saline lavage was used to reduce lung compliance. $\mathrm{CO}$ was continuously recorded with an electromagnetic flow probe placed around the aorta and pulmonary vascular resistance was calculated from left atrial and pulmonary artery pressures. Lung lavage reduced static compliance of the respiratory system but did not change $\mathrm{CO}$ during pressurelimited ventilation. During HFOV, $\mathrm{CO}$ was higher in animals after lung lavage at each $\overline{\mathbf{P}}$ aw. As $\overline{\mathbf{P}}$ aw was raised from 4 to $16 \mathrm{~cm} \mathrm{H}_{2} \mathrm{O}$ during $\mathrm{HFOV}, \mathrm{CO}$ decreased from $133 \pm 36$ to $87 \pm 31 \mathrm{ml} / \mathrm{min} \mathrm{kg}$ in animals with normal lungs and decreased from $153 \pm 33$ to $107 \pm 19 \mathrm{ml} / \mathrm{min} \mathrm{kg}$ after lung lavage (both $p<0.001$ ). Increasing $\overline{\mathrm{P}}$ aw was also associated with an increase in pulmonary vascular resistance both before and after lung lavage (both $p<$ 0.005). Changes in frequency did not significantly alter $\mathrm{CO}$ or pulmonary vascular resistance. We conclude that the interaction between the heart and lungs during HFOV is largely mediated by $\overline{\mathbf{P}}$ aw and compliance of the respiratory system. Furthermore, regardless of the degree of lung compliance, cardiac function may be impaired during HFOV as $\overline{\mathrm{P}}$ aw is elevated. (Pediatr Res 23:628-631, 1988)
\end{abstract}

\section{Abbreviations}

CO, cardiac output

HFOV, high-frequency oscillatory ventilation

Paw, mean airway pressure

PVR, pulmonary vascular resistance

Assisted ventilation has substantially reduced mortality in infants with respiratory failure. Unfortunately this reduced mortality has been accompanied by an increase in major complications such as air leaks and bronchopulmonary dysplasia. Inasmuch as these side effects are heavily influenced by certain

Received November 30, 1987; accepted February 10, 1988.

Correspondence Waldemar A. Carlo, M.D., Rainbow Babies and Children's Hospital, 2101 Adelbert Road, Cleveland, OH 44106.

Supported by the National Heart, Lung and Blood Institute Grant HL-07592 and by the American Lung Association of Northern Ohio.

Presented in part at the Annual Meeting of the American Lung Association, New Orleans, LA, May, 1987. ventilatory parameters, especially airway pressures $(1,2)$, new ventilators that enhance gas exchange while minimizing pressure delivery have been developed.

HFOV, delivers and withdraws small stroke volumes at very high frequencies. Because HFOV may enable adequate gas exchange to occur at reduced pressure swings, it may alleviate some of the complications of assisted ventilation. However, oxygenation during HFOV is largely dependent on $\bar{P}$ aw $(3,4)$. Inasmuch as increasing $\overline{\mathrm{P}}$ aw has been shown to depress CO (5-7), oxygen transport may be reduced despite an increase in arterial oxygenation.

Because the effect of $\overline{\mathrm{P}} \mathrm{aw}$ on cardiovascular function is dependent on the transpulmonary pressure, decreased lung compliance is thought to be associated with less impairment of CO. However, $\mathrm{CO}$ is difficult to assess in small infants and often blood pressure and heart rate are the only available means of assessing cardiovascular function. As a result, it remains unknown if during HFOV surfactant deficiency has a protective effect on $\mathrm{CO}$ as $\overline{\mathrm{P}}$ aw is increased. Therefore, the purpose of our study was to investigate the hemodynamic effects of controlled Paw and oscillatory frequency in an animal model during HFOV and to examine how these effects are modulated by changes in respiratory compliance.

\section{METHODS}

Seven cats $(3.0 \pm 0.6 \mathrm{~kg}$; mean $\pm \mathrm{SD})$ were anesthetized with an intraperitoneal injection of chloralose $(40 \mathrm{mg} / \mathrm{kg})$ and urethane $(250 \mathrm{mg} / \mathrm{kg})$. This mixture was also used to maintain anesthesia as needed throughout the duration of the study. Catheters were placed in the femoral artery (PE 90) to measure blood pressure and the femoral vein (PE 190) for the administration of fluids and anesthesia. An endotracheal tube (3.5 mm ID) was positioned above the carina through a tracheostomy and secured in place to prevent any air leaks. The cat was then placed on a pressure-limited, time-cycled conventional ventilator (Bourns BP200, $\mathrm{FiO}_{2}=0.21$ to 0.25 , peak inspiratory pressure $=12 \mathrm{~cm} \mathrm{H}_{2} \mathrm{O}$, positive and expiratory pressure $=2 \mathrm{~cm} \mathrm{H}_{2} \mathrm{O}$, inspiratory to expiratory times ratio $=1: 5, \overline{\mathrm{P}}$ aw $=4.5$, rate $=$ $12 / \mathrm{min})$.

A midsternal thoracotomy was performed and the heart was exposed after the pericardium was retracted. Left atrial pressure was recorded from a saline-filled pressure catheter (PE 190) placed in the left atrium through the left atrial appendage. A similar catheter was placed in the pulmonary artery through the right ventricular wall to record pulmonary artery pressure. All pressure transducers (Statham no. P23AC) were referenced to zero at the level of the mid-left atrium. An electromagnetic flow probe (Carolina Medical Electronics no. EMP-416) was placed around the aorta to continuously measure CO. PVR was obtained by taking the pressure difference between the pulmonary 
artery and left atrium and dividing by the $\mathrm{CO}$. To reexpand the lungs and drain the chest a multiholed tube was inserted through the chest wall and connected to a $10 \mathrm{~cm} \mathrm{H}_{2} \mathrm{O}$ negative pressure source. The pericardium was left open and the chest was closed in two separate airtight layers.

After a 30-min period, the animal was switched from conventional ventilation to HFOV (Mera Corp., Hummingbird no. BMO-20N) at a bias flow of 5 liter/min and an oxygen concentration of 21 to $25 \%$. Random combinations of $\bar{P}$ aw of 4, 8, 12, and $16 \mathrm{~cm} \mathrm{H}_{2} \mathrm{O}$ and frequencies of $3,6,12,16$, and $20 \mathrm{~Hz}$ were used. At each frequency, the volume generated by the oscillator was adjusted to produce a constant ventilator generated minute ventilation although the actual volume delivered to the animal was not controlled or measured. At each combination of $\bar{P}$ aw and frequency, values were obtained for $\mathrm{CO}$, left atrial pressure, and pulmonary artery pressure approximately $30 \mathrm{~s}$ after all three parameters reached steady state. This procedure was repeated until the entire range of $\bar{P}$ aw was covered at each frequency. Between the HFOV trials the animals were returned to conventional ventilation and end-tidal $\mathrm{pCO}_{2}$ was continually checked to ensure normocapnia (range $37-42 \mathrm{~mm} \mathrm{Hg}$ ) (Beckman LB-2). Arterial blood gases were measured (Corning 175) periodically and the $\mathrm{PO}_{2}$ was maintained above $100 \mathrm{~mm} \mathrm{Hg}$ (range 105-142 $\mathrm{mm} \mathrm{Hg}$ ).

Lung compliance was reduced by lavage, using $30 \mathrm{ml} / \mathrm{kg}$ of $37^{\circ} \mathrm{C}$ normal saline (8). Approximately $80 \%$ of the saline used for lavage was recovered. This procedure was performed twice and measurements of respiratory mechanics were obtained to confirm the reduction in compliance. Respiratory mechanic measurements were also repeated subsequently to ensure stability of the preparation. The $\mathrm{FiO}_{2}$ was raised to 1.0 during lung lavage to ensure normoxemia. During conventional ventilation, peak inspiratory pressure was raised to $16 \mathrm{~cm} \mathrm{H}_{2} \mathrm{O}(\overline{\mathrm{P}} \mathrm{aw}=5.2 \mathrm{~cm}$ $\mathrm{H}_{2} \mathrm{O}$ ) and the $\mathrm{FiO}_{2}$ was set at 0.40 . Approximately 30 min were allowed for blood pressure and $\mathrm{CO}$ to stabilize. Arterial blood gases were again controlled. The $\mathrm{PCO}_{2}$ was kept between 37 and $42 \mathrm{~mm} \mathrm{Hg}$ and the $\mathrm{PO}_{2}$ was kept above $100 \mathrm{~mm} \mathrm{Hg}$ (100-134 $\mathrm{mm} \mathrm{Hg}$ ). The animal was returned to HFOV using a bias flow of 5 liter/min and an oxygen concentration of $40 \%$. Frequency and $\bar{P}$ aw were varied in the same order as previously described.

Respiratory mechanics were assessed using the valve interrupter method $(9,10)$. Briefly, expiratory airflow is intermittently occluded permitting multiple measurements of alveolar pressure (Validyne no. MP45-18) and flow. Several of these sequential occlusions can be obtained during a single expiration. Volume is computed by electrically integrating airflow through a heated screen pneumotachometer (Hans Rudolph, no. 3700, Validyne MP45-1) and is then normalized to body weight. Compliance of the respiratory system is obtained by dividing the normalized volume by the pressure recorded during each interruption. Compliance curves were generated both before and after lung lavage.

To evaluate the efficacy of lung lavage in producing histopathological changes of lung injury, lung tissue was removed from the apical region of the lung and from the middle of the anterior and posterior lobes. The tissue was fixed in formalin overnight, embedded, cut, and then stained with hematoxylin and eosin. There was evidence of widespread and focal atelectasis, hemorrhage, and edema as well as desquamation of bronchial and bronchiolar epithelium.

All data were recorded on a six channel recorder (Gould Inc., model 260). Analysis of variance and Student's $t$ tests were used as appropriate. Compliance curves were fit to the equation: Vol $=\mathrm{a}[1-\exp (-\mathrm{b} \cdot \mathrm{Palv})]$ where $\mathrm{Vol}$ is volume above functional residual capacity and Palv is alveolar pressure obtained by the interrupter technique. This model was chosen for its convenience and minimal number of parameters. The exponential coefficients (b in each equation), obtained by nonlinear regression (BMDP3R), were chosen to compare the curves before and after lung lavage for statistical difference. All results are expressed as mean $\pm \mathrm{SD}$.

\section{RESULTS}

Respiratory system compliance decreased after lung lavage as illustrated in a typical animal in Figure 1. A similar curve was produced for each cat used in the study. Numerical values used to compare compliance before and after lung lavage were taken from the exponential coefficients of the curves as well as from the static compliance of the respiratory system measured at the highest lung volume. Average respiratory compliance for all cats as represented by the exponential coefficient of the compliance curve decreased from $0.097 \pm 0.031$ to $0.072 \pm 0.036 \mathrm{~cm} \mathrm{H}_{2} \mathrm{O}^{-1}$ after lung lavage $(p<0.05)$. Similarly, static compliance at maximum lung volume and pressure $\left(16 \mathrm{~cm} \mathrm{H}_{2} \mathrm{O}\right)$ decreased from $3.03 \pm 0.70$ to $2.08 \pm 0.83 \mathrm{ml} / \mathrm{cm} \mathrm{H}_{2} \mathrm{O} \mathrm{kg}(p<0.05)$.

Heart rate was not significantly altered by lavage $(204 \pm 24$ before and $197 \pm 17$ beats/min after lavage). Baseline $\mathrm{CO}$ and PVR values measured during conventional ventilation before and after lung lavage were not significantly different. Average CO during conventional ventilation before lavage was $115 \pm 24$ $\mathrm{ml} / \mathrm{min} \mathrm{kg}$ compared to $120 \pm 20 \mathrm{ml} / \mathrm{min} \mathrm{kg}$ after lavage. Similarly, PVR was $0.13 \pm 0.02$ before and $0.14 \pm 0.04 \mathrm{~cm} \mathrm{H}_{2} \mathrm{O}$ $\mathrm{min} \mathrm{kg} / \mathrm{ml}$ after lavage. All animals remained stable throughout the duration of the experiment as evidenced by $\mathrm{CO}$, heart rate, and static compliance.

In both normal and surfactant-deficient lungs $\mathrm{CO}$ decreased and PVR increased as Paw was elevated during HFOV (Figs. 2 and 3). As $\overline{\mathrm{P}}$ aw was increased from 4 to $16 \mathrm{~cm} \mathrm{H}_{2} \mathrm{O}, \mathrm{CO}$ decreased from $133 \pm 36$ to $87 \pm 31 \mathrm{ml} / \mathrm{min} \mathrm{kg}$ in normal lungs $(p<$ 0.001 ) and decreased from $153 \pm 33$ to $107 \pm 19 \mathrm{ml} / \mathrm{min} \mathrm{kg}$ in surfactant deficient lungs $(p<0.001)$. During HFOV, CO was significantly higher in cats after lung lavage at each $\overline{\mathrm{Paw}}_{\mathrm{a}}(p<$ $0.05)$. PVR increased in normal lungs from $0.13 \pm 0.07$ to 0.31 $\pm 0.11 \mathrm{~cm} \mathrm{H} \mathrm{H}_{2} \mathrm{O} \mathrm{min} \mathrm{kg} / \mathrm{ml}$ and in surfactant-deficient lungs from $0.12 \pm 0.05$ to $0.22 \pm 0.06 \mathrm{~cm} \mathrm{H}_{2} \mathrm{O} \operatorname{min~} \mathrm{kg} / \mathrm{ml}$ as $\overline{\mathrm{P}}$ aw was increased from 4 to $16 \mathrm{~cm} \mathrm{H}_{2} \mathrm{O}$ (both $p<0.005$ ). PVR was significantly less in surfactant deficient lungs compared to normal lungs for $\overline{\mathrm{P}}$ aw $>4 \mathrm{~cm} \mathrm{H} \mathrm{H}_{2} \mathrm{O}(p<0.01)$. Lowest values of end tidal $\mathrm{CO}_{2}$ during $\mathrm{HFOV}$ were $29 \pm 3 \mathrm{~mm} \mathrm{Hg}$ before lung lavage and $31 \pm 5 \mathrm{~mm} \mathrm{Hg}$ after lung lavage.

Changes in oscillatory frequency did not consistently change $\mathrm{CO}$ (Fig. 4). Slight changes in $\mathrm{CO}$ were seen throughout the investigated frequency range; however, these changes were not statistically significant. Similarly, there was no significant effect of frequency on PVR. However, increases in PVR did accompany decreases in $\mathrm{CO}$ depicted in Figure 4. Heart rate and blood pressure remained stable throughout the elevations in $\overline{\mathrm{P}}$ aw, pro-

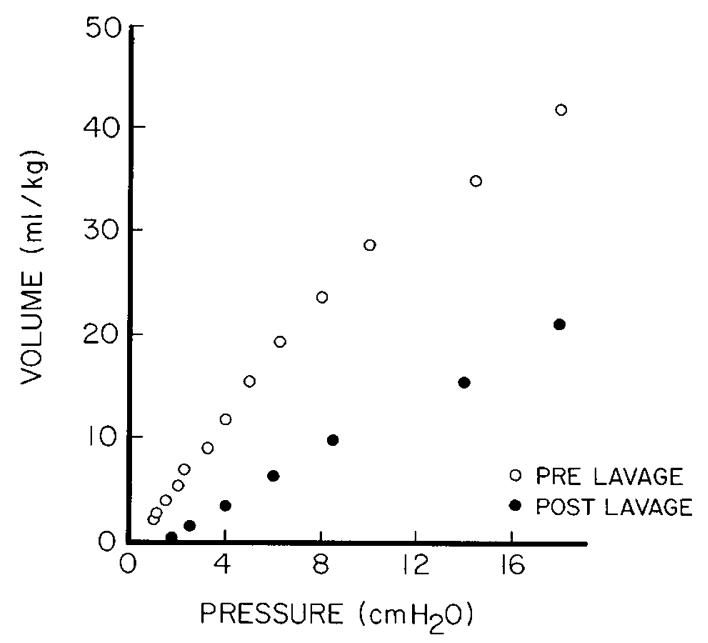

Fig. 1. Typical respiratory system compliance data obtained by the interrupter technique in a cat during passive expiration. Lung volume has been normalized to body weight. Compliance decreased after lung lavage. 


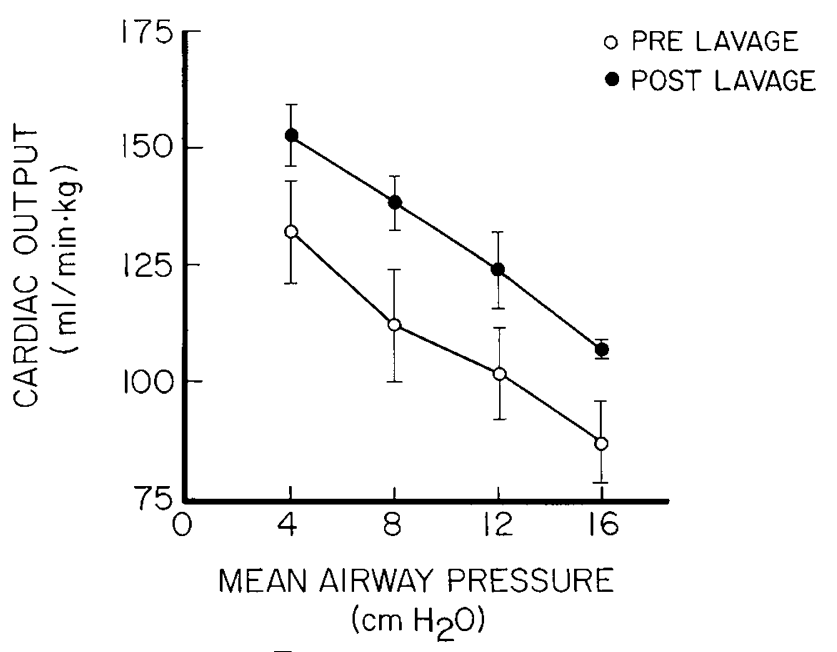

Fig. 2. The effect of $\bar{P}$ aw on $\mathrm{CO}$ in seven cats both before and after lung lavage. $\mathrm{CO}$ has been normalized to body weight. $\mathrm{CO}$ decreased with increasing $\bar{P}$ aw both before and after lung lavage. At each $\bar{P}$ aw, $\mathrm{CO}$ was higher after lung lavage.

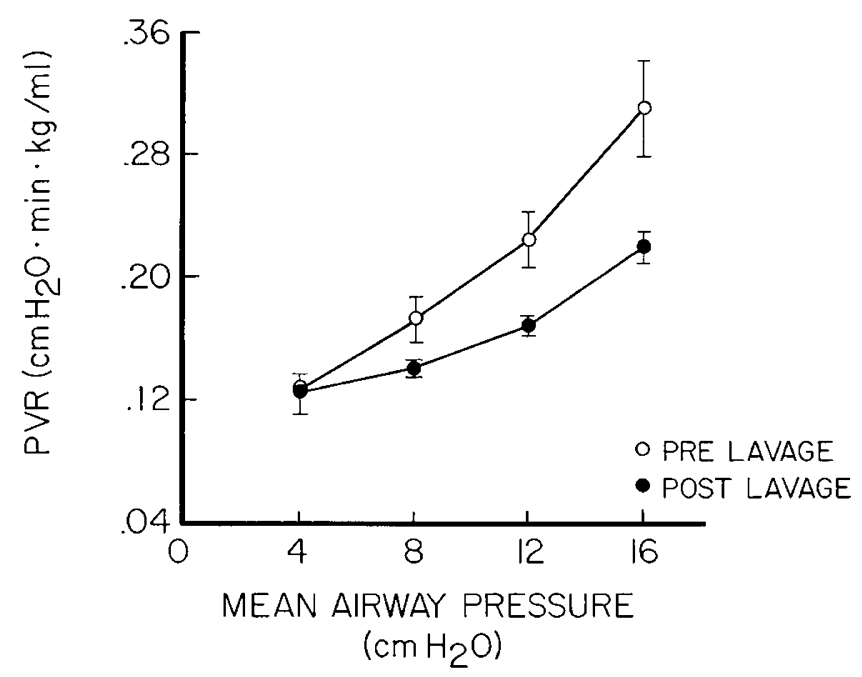

Fig. 3. The effect of $\bar{P}$ aw on PVR in seven cats both before and after lung lavage. Pulmonary vascular resistance increased as $\bar{P}$ aw was raised both before and after lung lavage. For $\overline{\mathrm{P}} \mathrm{aw}>4 \mathrm{~cm} \mathrm{H}_{2} \mathrm{O}$, PVR was significantly higher in normal lungs.

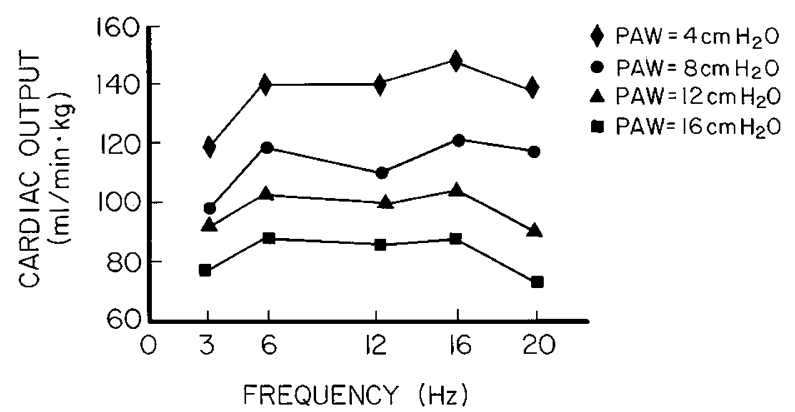

Fig. 4. The effect of oscillatory frequency on $\mathrm{CO}$ in seven cats with normal lungs. As $\bar{P}$ aw increased, $\mathrm{CO}$ decreased at each frequency. There was no consistent effect of frequency on $\mathrm{CO}$.

pressure remained stable throughout the elevations in Paw, providing no indication that $\mathrm{CO}$ was being depressed.

\section{DISCUSSION}

We have shown that cardiovascular depression is induced in this animal model as $\overline{\mathrm{P}}$ aw is raised from 4 to $16 \mathrm{~cm} \mathrm{H}_{2} \mathrm{O}$ during
HFOV regardless of the compliance status of the lungs. The concomitant increase in PVR that occurs as Paw is increased appears to partially mediate the observed fall in $\mathrm{CO}$. The reduction in respiratory system compliance produced by lung lavage appears to diminish the increase in PVR that occurs as airway pressure is raised (Fig. 3). This may explain why cardiovascular depression is not routinely seen in infants with respiratory distress syndrome (3).

We used the lung lavage method described by Lachmann et al. (8) to create a model of surfactant deficiency although this model may differ from respiratory distress syndrome as observed in premature infants. Inasmuch as we recovered only $80 \%$ of the saline used for lung lavage, it is possible that plasma volume expansion could have raised CO. However, by using periods of conventional ventilation before and after lavage as a baseline, we found that lavage produced no significant effect on those parameters including heart rate, $\mathrm{CO}$, and PVR. A limitation of our study is that although we controlled the gas volumes generated by the oscillator, we did not measure or control delivered stroke volumes during HFOV. Controlling stroke volume during highfrequency ventilation is extremely difficult due to its dependence on many parameters, such as frequency and endotracheal tube size. Furthermore, techniques for measuring tidal volumes at high frequencies may be unreliable $(3,11)$.

The hypocapnia induced by HFOV should not alter our results because previous studies of more severe hypocapnia produce no adverse effects on myocardial function (12). Furthermore, HFOV produced comparable hypocapnia in both normal and lavaged lungs.

Cardiovascular depression due to elevated $\bar{P}$ aw during conventional ventilation of normal lungs is well documented and has been attributed to a variety of mechanisms including mechanical effects on the heart and vasculature (7), neurally mediated effects (13), and humoral effects (14). The fall in CO can be due to reductions in heart rate, preload, and contractility as well as increases in afterload. We observed no change in heart rate over the course of the study and therefore attributed the fall in CO to a reduction in stroke volume. The elevations in $\bar{P}$ aw would be expected to increase intrathoracic pressure and reduce preload by diminishing venous return as has been observed with other types of mechanical ventilation (15). Increases in right ventricular afterload occurred as a result of elevations in $\bar{P}$ aw as evidenced by the rise in PVR. Together, these resultant preload and afterload effects reduce blood flow through the lungs, ultimately reducing $\mathrm{CO}$. Although we did not assess contractility, it is unlikely that it was altered by brief periods of change in $\overline{\text { Paw. }}$.

Our results of the effect of $\overline{\mathrm{P}}$ aw on $\mathrm{CO}$ are best explained by the mechanical interactions between the heart and lungs as other investigators have reported. Rankin et al. (7) examined the mechanical and dimensional changes that occur in the dog heart during change in $\overline{\mathrm{P}}$ aw and found that increases in $\overline{\mathrm{P}}$ aw decrease preload in the left ventricle which reduces stroke volume. They hypothesized that the reduction in left ventricular preload was due to a decrease in blood flow through the lungs caused by an increase in PVR. Interestingly, as observed by Robotham et al. (16), there is no change in right ventricular end diastolic volume. It is thought that the reduction in volume caused by decreased venous return secondary to increased intrathoracic pressure is offset by the increase in right ventricular afterload produced by the increase in PVR. They concluded that the reduced preload effects and increased afterload effects contributed equally in reducing $\mathrm{CO}$ and that the functional changes in the heart were mainly mechanical effects due to airway pressure.

A secondary focus of our study was to examine how PVR is modulated by decreased lung compliance induced by surfactant deficiency. It is known that changes in lung inflation directly affect PVR $(15,17)$. As lung inflation increases, the alveolar capillaries are lengthened and compressed. Both of these dimensional changes act to raise PVR. It has been postulated that when alveolar pressure exceeds pulmonary venous and capillary pressure, pulmonary blood flow decreases due to increased PVR (18). 
This mechanism may explain the increase in PVR that we have found herein and that has been observed in other models in which pulmonary blood flow and pressure were controlled (19). In addition, we have also shown that decreasing lung compliance reduces PVR for a given $\overline{\mathrm{P}}$ aw (Fig. 3). This reduction in PVR appears to be due to a reduction in transpulmonary pressure and volume after lung lavage, and may account for the difference in $\mathrm{CO}$ observed in Figure 2. We did not directly evaluate the effect of lung volume on PVR. However, lung volume is likely to be reduced in surfactant deficient lungs compared to normal lungs for a given $\bar{P}$ aw (Fig. 1). A reduction in lung volume could account for the decrease in PVR observed in the surfactantdeficient animals.

To make our model as realistic as possible, we imposed no control on pulmonary blood flow or pressure drop across the pulmonary vascular bed. These parameters were permitted to change naturally in response to each change in Paw. However, the interpretation of a change in PVR after an experimental intervention (lavage) can be misleading when both blood flow and vascular pressure are allowed to change simultaneously (20). Inasmuch as the pressure drop in our study was not different between normal and surfactant-deficient lungs, the fall in $\mathrm{CO}$ that occurred as $\overline{\mathrm{P}}$ aw is elevated may be attributed to an increase in PVR.

The effects of changes in lung compliance on the relationship between $\overline{\mathrm{P}}$ aw and $\mathrm{CO}$ have been studied in piglets with normal and reduced lung compliance during conventional ventilation (21). A linear decrease in $C O$ was observed as $\overline{\mathrm{P}}$ aw was raised in piglets with normal lungs. When compliance was reduced by lavage, $\mathrm{CO}$ was depressed only at higher $\overline{\mathrm{P}}$ aw. We observed depression of $\mathrm{CO}$ over the entire range of $\overline{\mathrm{P}}$ aw, although this could be explained by the smaller decrease in compliance used in our study. An increase in $\mathrm{CO}$ was also observed in rabbits with decreased lung compliance after lung lavage during HFOV administered at a constant $\overline{\mathrm{P}}$ aw of $15 \mathrm{~cm} \mathrm{H}_{2} \mathrm{O}(22)$. Our results expand on these findings by including a range of controlled $\overline{\mathrm{P}}$ aw and frequencies during HFOV and we propose that the discrepancy in $\mathrm{CO}$ between normal and surfactant deficient lungs may be partially explained by changes in PVR illustrated in Figure 3.

The occurrence of cardiac depression during assisted ventilation is not a common clinical problem in infants with respiratory distress syndrome $(1,3)$. This has been attributed to the decreased lung compliance that causes a reduction in the transmission of airway pressure to the intrathoracic structures. However, $\mathrm{CO}$ measurements of infants are seldom used and whereas heart rate and blood pressure are used to assess cardiac function, they do not always provide a true reflection of the cardiovascular state of the infant as we have observed in our model. As suggested by our data, cardiac depression will also occur in surfactant-deficient lungs if $\overline{\text { Paw }}$ is markedly increased.

The recommendations of a recent conference on high-frequency ventilation in infants suggested that further evaluation of ventilatory functions and interactions are needed (23). These include the areas of respiratory mechanics and cardiopulmonary interactions that we have related herein. Although our results were obtained during HFOV, they may also be applicable to other forms of high-frequency ventilation and conventional ventilation because the changes appear to be mediated by mechanical interactions between the heart and lungs.
Acknowledgments. The authors acknowledge the thoughtful comments by Drs. R. J. Martin, S. Robertson, G. Saidel, R. Jarvis, and B. Effron, and the assistance in preparation of the manuscript by Carolyn Grier and Karen Toil.

\section{REFERENCES}

1. Carlo WA, Martin RJ 1986 Principles of neonatal assisted ventilation. Pediatr Clin North Am 33:221-237

2. Ogata ES, Gregory GA, Kitterman JA, Phibbs RH, Tooley WH 1976 Pneumothorax in the respiratory distress syndrome: incidence and effect on vital signs, blood gases and pH. Pediatrics 58:177-183

3. Marchak BE, Thompson WK, Duffty P, Miyaki T, Bryan MH, Bryan AC, Froese AB 1981 Treatment of RDS by high-frequency oscillatory ventilation: a preliminary report. Pediatrics 99:287-292

4. Thompson WK, Marchak BE, Froese AB, Bryan AC 1982 High-frequency oscillation compared with standard ventilation in pulmonary injury model. J Appl Physiol 52:543-548

5. Biondi J, Hines R, Rafferty T, Rogol P, Scott W, Barash P 1986 The Effect of high-frequency positive pressure ventilation on right and left ventricular function. Anesth Analg 65:679-682

6. Calvin JE, Baer RW, Glantz SA 1985 Pulmonary artery constriction produces a greater right ventricular dynamic afterload than lung microvascular injury in the open chest dog. Circ Res 56:40-56

7. Rankin JS, Olsen CO, Arentzen CE, Tyson GS, Maier G, Smith PK, Hammon JW, Davis JW, McHale PA, Anderson RW, Sabiston DC 1982 The effects of airway pressure on cardiac function in intact dogs and man. Circulation 66:108-120

8. Lachmann B, Robertson B, Vogel J 1980 In vivo lung lavage as an experimental model of the respiratory distress syndrome. Acta Anaesth Scand 24:231-236

9. Carlo WA, Goldthwait DA, Korvenranta HJ, Traverse JH Chatburn RL 1986 Changes in lung volume and airflow alter intrabreath pulmonary mechanics in normal and surfactant deficiency. Am Rev Respir Dis 133:A152

10. Gottfried SB, Rossi A, Calverley MA, Zocchi L, Milic-Emili J 1984 Interrupter technique for measurement of respiratory mechanics in anesthetized cats. $J$ Appl Physiol 56:681-690

11. Weisberger SA, Carlo WA, Fouke JM, Chatburn RL, Tillander T, Martin RJ 1986 Measurement of tidal volume during high-frequency jet ventilation. Pediatr Res 20:45-48

12. Coetzee A, Holland D, Foex P, Ryder A, Jone L 1984 The effect of hypocapnia on coronary blood flow and myocardial function in the dog. Anesth Analg 63:991-7

13. Cassidy SS, Eschenbacher WL, Johnson RL 1979 Reflex cardiovascular depression during unilateral lung hyperinflation in the dog. J Clin Invest 64:620626

14. Grindlinger GA, Manny J, Justice R, Dunham B, Shepro D, Hechtman HB 1979 Presence of negative inotropic agents in canine plasma during positive end-expiratory pressure. Circ Res 45:460-467

15. Scharf SM, Ingram RH 1977 Effects of decreasing lung compliance with oleic acid on the cardiovascular response to PEEP. Am J Physiol 233:H635-641

16. Robotham JL, Lixfeld W, Holland L, MacGregor D, Bromberger-Barnea B Permutt S, Rabson JL 1980 The effects of positive and end-expiratory pressure on right and left ventricular performance. Am Rev Respir Dis 121:677-683

17. Howell JBL, Permutt S, Proctor DF, Riley RL 1961 Effect of inflation of the lung on different parts of pulmonary vascular bed. J Appl Physiol 16:71-76

18. Henning RJ 1986 Effects of positive end-expiratory pressure on the right ventricle. J Appl Physiol 61:819-826

19. Roos A, Thomas LJ, Nagel EL, Prommas DC 1961 Pulmonary vascular resistance as determined by lung inflation and vascular pressures. $\mathbf{J}$ Appl Physiol 16:77-84

20. Fishman AP 1985 The pulmonary circulation. In: Fishman AP (ed) The Respiratory System. American Physiology Society, Baltimore, pp 116-120

21. Mirro R, Busija D, Green R, Leffler C 1987 Relationship between mean airway pressure, cardiac output, and organ blood flow with normal and decreased respiratory compliance. J Pediatr 111:101-106

22. Mirro R, Tamuru M, Kawano T 1985 Systemic cardiac output and distribution during high-frequency oscillation. Crit Care Med 13:724-727

23. Special conference report: high-frequency ventilation for immature infants, 1983. Pediatrics $71: 280-287$ 